\title{
Influence of gum arabic coating enriched with calcium chloride on physiological, biochemical and quality responses of mango (Mangifera indica L.) fruit stored under low temperature stress
}

\begin{abstract}
Effects of gum arabic (GA) $10 \%$ and calcium chloride (CA) $3 \%$ on the physiological, biochemical and quality responses of mango (Mangifera indica L. cv. Choke Anan) fruit were investigated. Fruit were stored at $6{ }^{\circ} \mathrm{C}$ and $90 \%$ relative humidity for $28 \mathrm{~d}$ and then transferred to $25{ }^{\circ} \mathrm{C}$ for an additional $5 \mathrm{~d}$ shelf life. Significant $(\mathrm{P} \leq 0.05)$ differences were observed in fruit treated with CA 3\% and GA 10\% as compared to the control. The combined treatment of CA $3 \%$ and GA $10 \%$, significantly alleviated chilling injury, malondialdehyde (MDA) content and electrolyte leakage than the control fruit. This treatment reduced the increase in hydrogen peroxide $\left(\mathrm{H}_{2} \mathrm{O}_{2}\right)$ content, superoxide anion $\left(\mathrm{O}_{2 \cdot}{ }^{-}\right)$production rate and enhanced DPPH radical scavenging activity. Furthermore, GA $10 \%$ alone or in combination with CA 3\% effectively inhibited the loss of total phenolic content and ascorbic acid. The result of transmission electron microscopy confirmed that treated fruit maintained cell membrane integrity. These results suggest that application of GA $10 \%$ coating combined with CA 3\% might be enhanced low temperature tolerance by improving the antioxidant defense system and reducing oxidative damage of mango fruit.
\end{abstract}

Keyword: Mango; Gum arabic; Calcium chloride; Low temperature; Oxidative stress; Antioxidant 